\title{
Sistem Informasi Seleksi Calon Ketua Himpunan Menggunakan Metode SAW Pada Himpunan Sistem Informasi STMIK Adhi Guna
}

\author{
Syarifah Fitrah Ramadhani ${ }^{1)}$, Eric Alfonsius ${ }^{2)}$, M. Yusuf Jumain ${ }^{3)}$ \\ 1), 2), 3) Sistem Informasi, STMIK Adhi Guna Palu \\ Jl. Undata No. 3, Besusu Barat, Palu Timur, Palu 94111 \\ Email : syarifahfr@stmikadhiguna.ac.id ${ }^{1)}$, ericlenak@gmail.com ${ }^{2)}$, myusuf.adhiguna@gmail.com $^{3}{ }^{3}$
}

\begin{abstract}
Abstrak
Penelitian ini bertujuan untuk membangun Sistem Informasi Seleksi Calon Ketua Himpunan Menggunakan Metode SAW Pada Himpunan Sistem Informasi STMIK Adhi Guna Palu. Pengumpulan data menggunakan observasi, wawancara, dan dokumentasi. Tujuan lain dalam pengembangan sistem adalah agar dengan adanya sistem ini dapat memberikan rekomendasi bakal calon ketua himpunan yang sesuai dengan apa yang diharapkan oleh mahasiswa sistem informasi STMIK Adhi Guna. Metode SPK SAW digunakan sebagai metode perhitungan berdasarkan dari masukan penilaian yang diberikan mahasiswa terhadap bakal calon ketua himpunan. Metode pengembangan sistem dalam penelitian ini menggunakan metode waterfall. Alat bantu pengembangan sistem menggunakan Unified Modeling Language. Teknik pengujian sistem menggunakan metode uji Blackbox dengan menguji beberapa item seperti simpan, edit dan hapus data. Hasil penelitian menunjukkan bahwa dari 50 kali uji dalam metode Blackbox menunjukkan hasil 100\% yang berarti bahwa kesuksesan sistem berhasil 100\%. Kesimpulan yang didapat adalah sistem yang dihasilkan dapat berjalan sesuai dengan yang diharapkan oleh peneliti.
\end{abstract}

Kata Kunci-Sistem Informasi, Pemilihan Ketua Himpunan, Metode SAW.

\begin{abstract}
This study aims to build an Information System for the Selection of Candidates for the Chairperson of the Association Using the SAW Method in the Information System Association of STMIK Adhi Guna Palu. Collecting data using observation, interviews, and documentation. Another goal in developing the system is that this system can provide recommendations for prospective association leaders in accordance with what is expected by STMIK Adhi Guna information system students. The SPK SAW method is used as a calculation method based on the input assessments given by students to prospective association leaders. The system development method in this study uses the waterfall method. System development tools using the Unified Modeling Language. The system testing technique uses the Blackbox test method by testing several items such as saving, editing and deleting data. The results showed that from 50 tests the Blackbox method showed 100\% results, which means that the success of the system was $100 \%$ successful. The conclusion is that the resulting system can run as expected by the researcher.
\end{abstract}

Keywords - Information Systems, Election of Association Chair, SAW Method 


\section{PENDAHULUAN}

Himpunan Mahasiswa Program Studi Sistem Informasi (HMPS-SI) adalah organisasi mahasiswa di tingkat jurusan pada suatu perguruan tinggi yang menjadi media bagi anggotanya untuk mengembangkan pola pikir, potensi, dan kepribadian yang berkaitan dengan disiplin ilmu sistem informasi agar siap terjun ke masyarakat. HMPS-SI berada di tingkat jurusan dan berada di bawah koordinasi BEM (Badan Eksekutif Mahasiswa), sehingga seluruh kegiatannya harus diketahui BEM.

Himpunan Mahasiswa Progam Studi Sistem Informasi (HMPS-SI) STMIK Adhi Guna berdiri sejak tahun 2001, di mana HMPS-SI adalah sebuah organisasi dalam jurusan sistem informasi yang ada di STMIK Adhi Guna yang berperan sebagai wadah mahasiswa untuk menyampaikan masalah atau keluhan yang tidak sesuai dengan ketentuan atau aturan yang berlaku pada jurusan tersebut.

Dalam HMPS-SI, proses pemilihan ketua himpunan yang ada saat ini hanya melakukan pendekatan kepada dewan senior karena peran dewan senior sangat berpengaruh dalam proses pemilihan calon ketua himpunan. Hal inilah yang menjadi permasalahan utama karena dalam pemilihan calon ketua himpunan haruslah mahasiswa/mahasiswi yang memiliki reputasi terbaik dari segi akademik kepemimpinan dan bertanggung jawab pada semua aspek.

Pemilihan ketua Himpunan Mahasiswa Progam Studi Sistem Informasi (HMPS-SI) masih menggunakan seleksi calon ketua ketua himpuan yang tidak efesien. Adapun kekurangan sistem seleksi yang berjalan saat ini adalah calon ketua himpunan yang diusulkan tidak memenuhi krateria yang diharapkan oleh mahasiswa himpunan. Selain itu tidak adanya transparansi calon ketua himpunan sehingga sebagian mahasiswa kadang tidak mengetahui mengenai calon ketua ataupun ketua yang sudah terpilih nantinya. Oleh karena itu solusi yang ditawarkan dalam peneltian ini adalah membuat suatu sistem informasi yang dapat dijadikan sebagai media informasi mengenai calon-calon ketua himpunan. Sistem ini juga diharapkan dapat menyeleksi seluruh mahasiswa sistem informasi yang berpotensi yang menjadi kadidat atau calon ketua himpunan dengan menggunakan metode SAW (Simple Additive Weighting) dan didasarkan pada beberapa krateria yang ada seperti: IPK terakhir, keaktifan kegiatan organisasi dan kepemimpinan.

\section{METODE PENELITIAN}

Metode Penelitian yang digunakan dalam Penelitian ini merujuk pada proses pengembangan sistem yang ada. Setelah melakukan observasi dan pengumpulan data, maka didapatkan hasil berikut ini: 2.1 Prosedur Penelitian

Pada Gambar 1 menunjukkan proses tahapan pengembangan sistem informasi yang dimulai dari Identifikasi Masalah, Studi Literatur topik terkait Penelitian serta Analisa sistem dan data yang ditemukan pada waktu observasi sampai dengan perancangan dan uji coba (implementasi).

\subsubsection{Identifikasi Permasalahan}

Dari observasi awal yang dilakukan, masih terdapat beberapa kendala Seleksi calon ketua yang ada tidak efektik karena hanya melakukan endekatan dengan desan senior, dan Ketua himpunan yang terpilihtidak sesuai dengan kreteria calon ketua himpunan yang ada. 


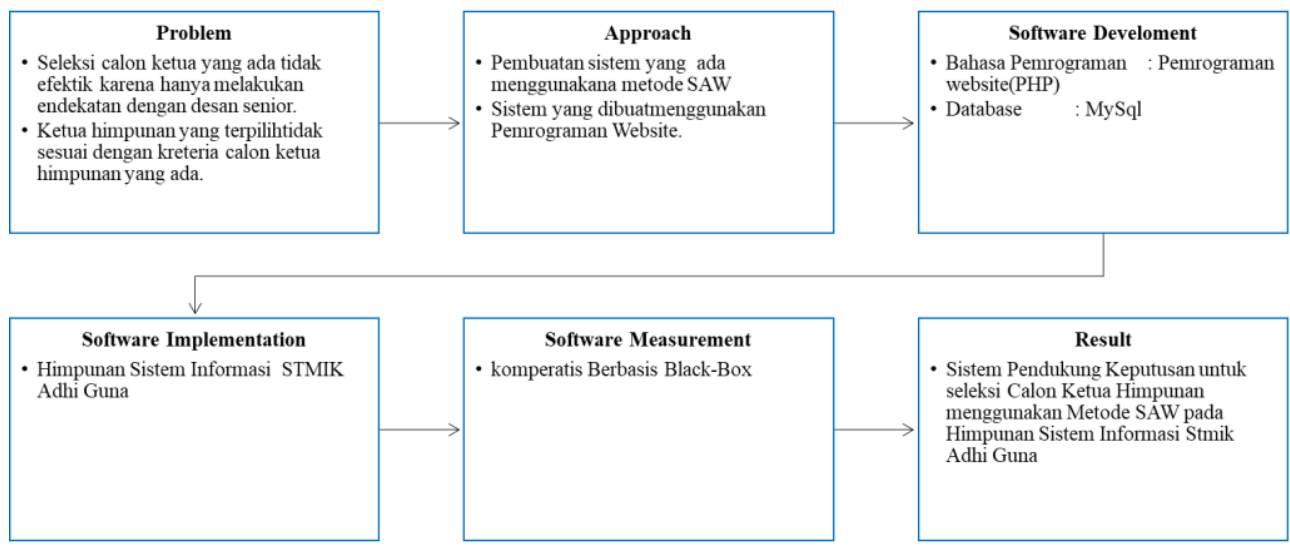

\subsubsection{Studi Literatur}

Gambar 1. Alur Penelitian

Studi literatur yang digunakan dalam Penelitian ini merujuk pada beberapa Penelitian yang berkaitan dari segi topik yang dibahas.

a. Perancangan Sistem

Perancangan [3] adalah tahapan awal dalam fase rekayasa perangkat lunak dan pembuatan prototipe alat. Perancangan pun dapat berupa proses penerapan berbagai macam metode dan Teknik serta analisa yang bertujuan untuk mendefinisikan serta membuat model yang terdiri dari satu proses atau satu sistem secara detail dalam tahapan realisasi sistem tersebut sehingga Fase ini dapat disebut core atau inti dari proses rekayasa perangkat lunak. Fase perancangan terdiri dari: Perancangan Database, Perancangan Arsitektur serta Perancangan interface/tampilan dari sistem yan akan dibangun tersebut. [4] Setelah fase perancangan akan menghasilkan tahapan selanjutnya membuat prototipe aplikasi yang akan dibuat melalui tahapan coding dan implementasi desain yang telah dibuat.

b. Definisi Sistem Pendukung Keputusan

Sistem Pendukung Keputusan (SPK) pertama kali diungkapkan pada awal tahun 1970-an oleh Michael S. Scott Mortondengan istilah Management Decision System. Sistem tersebut adalahsuatu sistem yang berbasis komputer yang ditunjukan untuk membantu pengambil keputusan dengan memanfaatkan data dan model tertentuuntuk memecahkan berbagai persoalan yang tidak terstruktur (Dewanto,2015).

c. Definisi Simple Additive Weighting (SAW)

Metode Simple Additive Weighting ( $S A W$ ) sering juga dikenal istilah metode penjumlahan terbobot. Konsep dasar metode SAW adalah mencari penjumlahan terbobot dari rating kinerja pada setiap alternatif pada semua atribut.

Metode SAW merupakan metode yang paling terkenal dan biasa digunakan untuk Multiple Attribute Decision Making (MADM). Dalam praktek MADM, jika kita mengasumsikan adanya hubungan yang saling independen antar kriteria dan setelah menghitung bobot relative dan skor kinerja masing-masing kriteria, maka

metode SAW merupakan metode yang sesuai untuk membuat perankingan dari alternatifalternatif yang ada.

Simple Additive Weighting (SAW) ini mengharuskan pembuat keputusan menentukan bobot bagi setiap atribut. Skor total untuk alternatif diperoleh dengan menjumlahkan seluruh hasil perkalian antara rating (yang dapat dibandingkan lintas atribut) dan bobot 
tiap atribut. Rating tiap atribut haruslah bebas dimensi dalam arti telah melewati proses normalisasi matriks sebelumnya.

\subsubsection{Desain (Perancangan)}

Desain dalam Penelitian ini merujuk pada desain proses dan desain interface. Adapun secara lebih detail dijelaskan sebagai berikut:

a. Desain Proses

Desain proses yang ada dalam Penelitian ini didasari dari proses analisis sistem berjalan dan analisis sistem. Adapun desain proses yang ada dalam Penelitian ini terdiri dari beberapa proses yakni pembuatan use case diagram yang ditunjukkan pada gambar 2 .

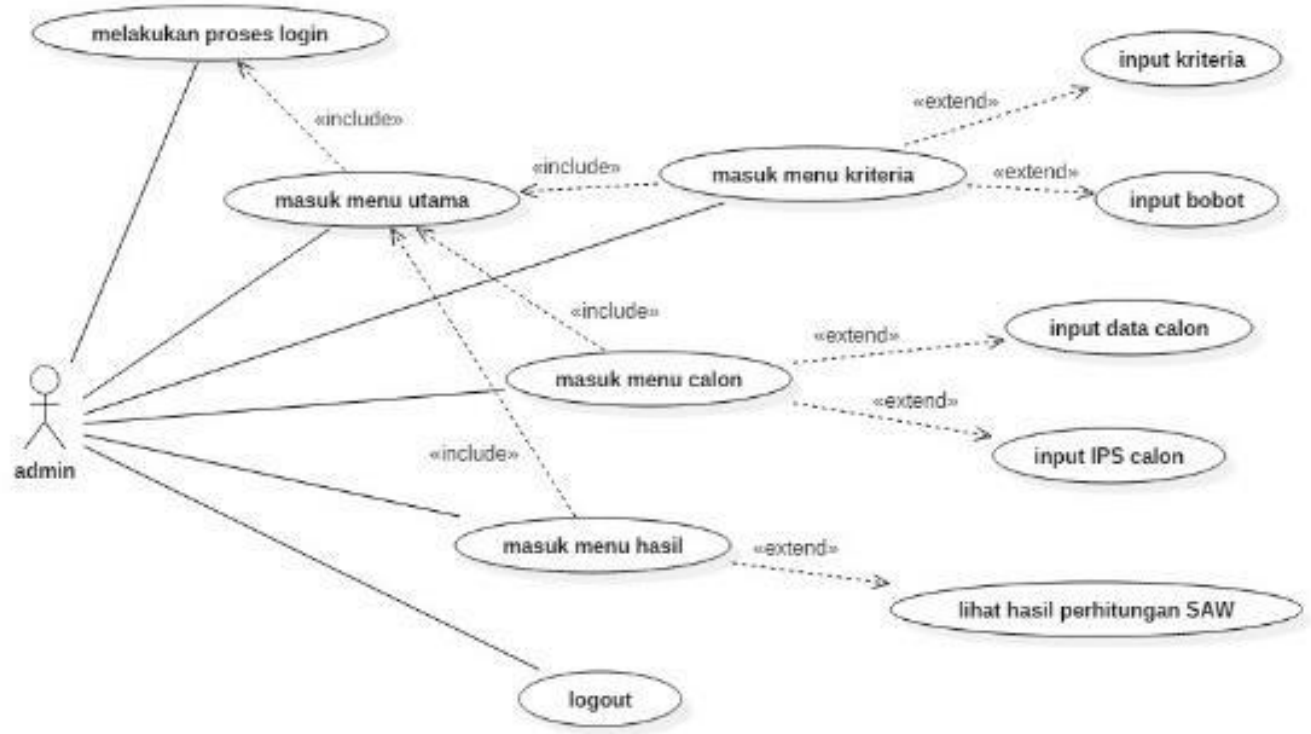

Gambar 2. Use Case Diagram

b. Desain Interface

Desain interface yang ada dalam Penelitian ini ditunjukkan pada gambar 3.
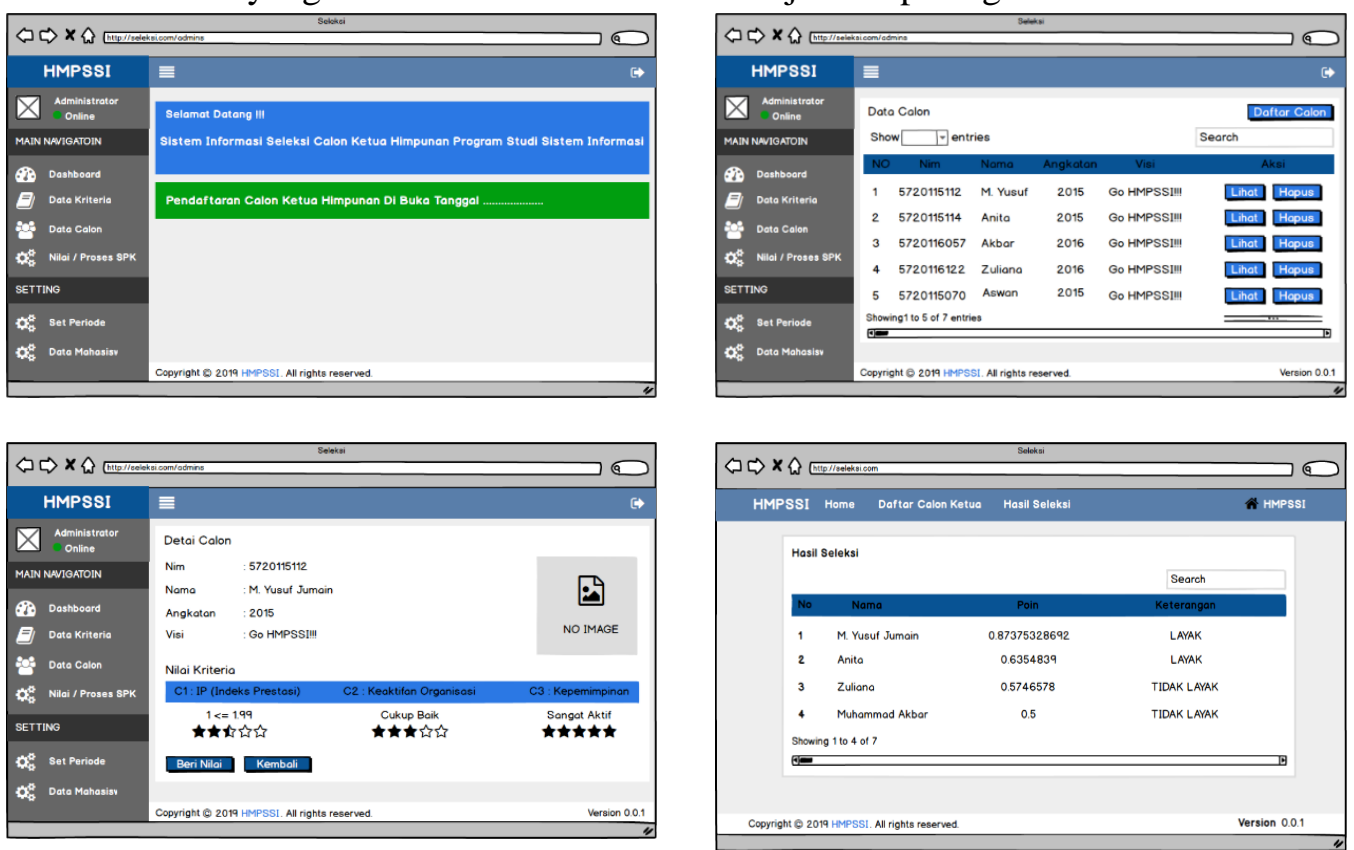

Gambar 3. Desain Tampilan Interface 


\section{HASIL DAN PEMBAHASAN}

Hasil dan pembahasan yang ada dalam Penelitian ini merujuk pada hasil implementasi tampilan sistem informasi setelah dijalankan dan hasil pengujian sistem dengan menggunakan pengujian kualitatif yakni dengan meminta tanggapan kuesioner dari pengguna sistem ini sebagai berikut:

\subsection{Hasil Implementasi}

Implementasi merupakan tahap penerapan desain rancangan web yang ada sebelumnya. Dalam tahap ini Penulis melakukan pengkodean sistem berdasarkan dari use case dan desain rancangan web. Adapun hasil implementasi dari pengkodean sistem tersebut ditunjukkan pada gambar 4 berikut ini.
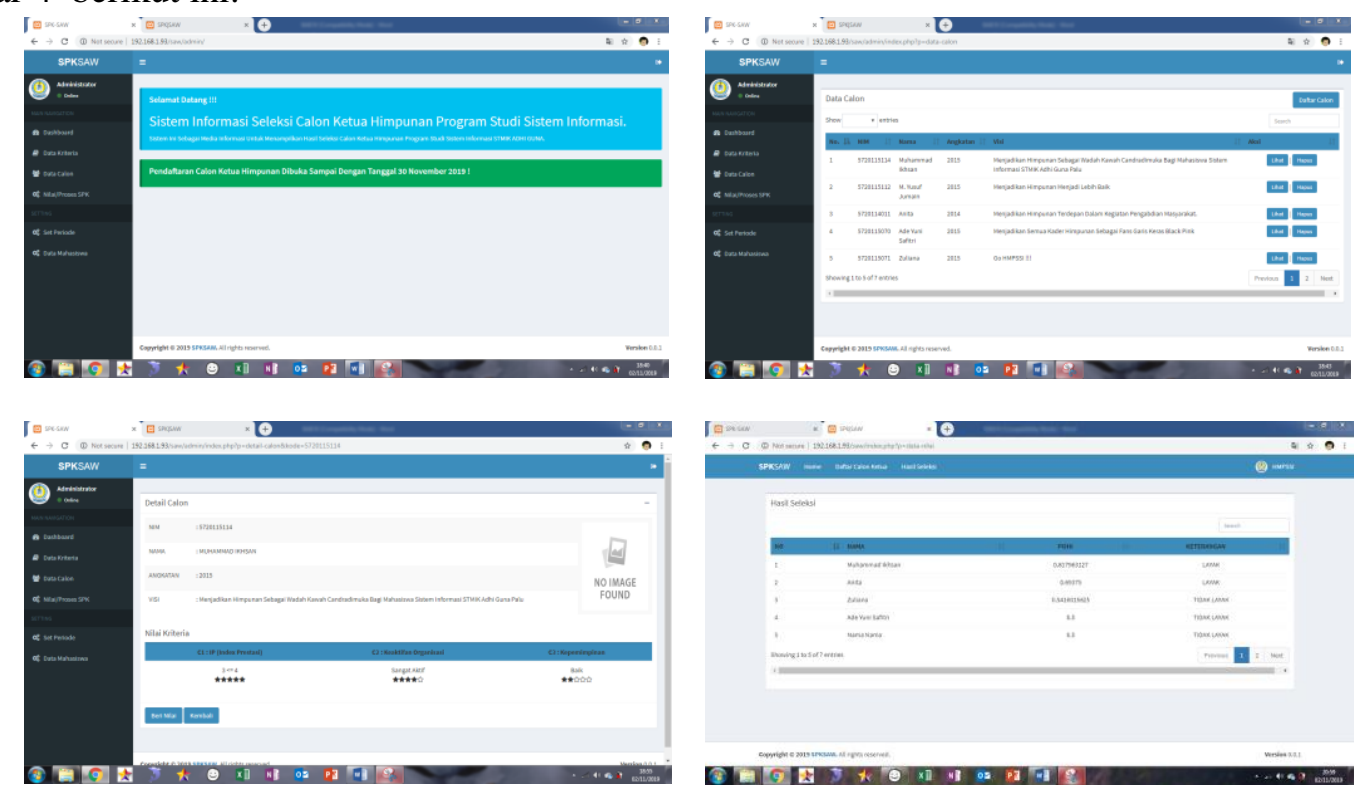

Gambar 5. Hasil Implementasi Sistem Informasi Seleksi Calon Ketua Himpunan (Tampilan Admin Panel)

\subsection{Hasil Pengujian}

\subsubsection{Pengujian Metode Simple Additive Weighting}

1. Menentukan Alternatif

Alternatif merupakan bakal calon ketua himpunan sistem informasi yang akan dipilih. Di dalam sistem yang peneliti kembangkan setiap mahasiswa aktif pada jurusan sistem informasi dapat mencalonkan diri. Untuk pengujian sistem, peneliti menggunakan tiga sampel sebagai alternatif. Adapaun alternatif tersebut dapat dilihat pada tabel berikut.

Tabel 1

Data Sampel Alternatif

\begin{tabular}{|c|c|c|}
\hline No. & Nama & Simbol \\
\hline 1 & M. Yusuf Jumain & $\mathrm{A} 1$ \\
\hline 2 & Ahmad & A2 \\
\hline 3 & Afriadin & A3 \\
\hline
\end{tabular}

2. Menentukan Kriteria Penilaian

Tahap selanjtnya adalah menentukan kriteria penilaian dan bobot nilai dari setiap kriteria yang akan digunakan. Adapun kriteria tersebut dapat dilihat pada tabel berikut. 
Tabel 2

Kriteria Penilaian Dan Bobot Nilai

\begin{tabular}{|c|c|l|c|}
\hline No. & Notasi & \multicolumn{1}{|c|}{ Kriteria Penilaian } & Bobot Setiap Alternatif \\
\hline 1 & C1 & IP (Indeks Prestasi) & 50 \\
\hline 2 & C 2 & Keaktifan Organisasi & 30 \\
\hline 3 & C 3 & Kepemimpinan & 20 \\
\hline
\end{tabular}

Selanjutnya pada tiap-tiap kriteria, peneliti menentukan acuan penilaian dan bobot nilai. Adapun detail kriteria tersebut dapat dilihat pada tabel berikut.

Tabel 3

Detail Kriteria IP (Indeks Prestasi) Dan Bobot Nilai

\begin{tabular}{|c|l|c|}
\hline No. & \multicolumn{1}{|c|}{ Detail Kriteria } & Bobot \\
\hline 1 & $3<=4$ (3 kurang dari sama dengan 4) & 100 \\
\hline 2 & $2<=2.99$ (2 kurang dari sama dengan 2.99) & 75 \\
\hline 3 & $1<=1.99$ (1 kurang dari sama dengan 1.99) & 25 \\
\hline 4 & $<1$ (kurang dari 1) & 0 \\
\hline
\end{tabular}

Tabel 4

Detail Kriteria Keaktifan Dalam Organisasi Dan Bobot Nilai

\begin{tabular}{|c|l|c|}
\hline No. & \multicolumn{1}{|c|}{ Detail Kriteria } & Bobot \\
\hline 1 & Sangat Aktif & 100 \\
\hline 2 & Cukup Aktif & 75 \\
\hline 3 & Kurang Aktif & 25 \\
\hline 4 & Tidak Aktif & 0 \\
\hline
\end{tabular}

Tabel 5

Detail Kriteria Kepemimpinan Dan Bobot Nilai

\begin{tabular}{|c|l|c|}
\hline No. & \multicolumn{1}{|c|}{ Detail Kriteria } & Bobot \\
\hline 1 & Sangat Baik & 100 \\
\hline 2 & Baik & 75 \\
\hline 3 & Cukup Baik & 25 \\
\hline 4 & Kurang Baik & 0 \\
\hline
\end{tabular}

3. Menentukan rating kecocokan setiap alternatif pada kriteria

Dalam penentuan rating kecocokan maka nilai dari masing-masing kriteria dimasukan kedalam tabel rating kecocokan yang telah disesuaikan dengan nilai dari tabel kriteria. Adapun data rating kecocokan dari setiap alternatif dapat dilihat pada tabel berikut :

Tabel 6

Rating Kecocokan dari Setiap Alternatif pada Setiap Kriteria

\begin{tabular}{|c|c|c|c|c|}
\hline \multirow{2}{*}{ No } & \multirow{2}{*}{ Alternatif } & \multicolumn{3}{|c|}{ Kriteria } \\
\cline { 3 - 5 } & & C1 & C2 & C3 \\
\hline 1 & A1 & 100 & 25 & 25 \\
\hline 2 & A2 & 75 & 25 & 0 \\
\hline 3 & A3 & 75 & 75 & 0 \\
\hline
\end{tabular}

4. Menentukan nilai transformasi ke dalam matrix $X$ yang merupakan nilai dari hasil Tabel 4.37. Matrix keputusan dibentuk dari Tabel 4.37 sebagai berikut :

$$
X=\left\{\begin{array}{ccc}
100 & 25 & 25 \\
75 & 25 & 0 \\
75 & 75 & 0
\end{array}\right\}
$$

5. Memberikan nilai bobot $(\mathrm{W})$ berdasarkan tingkat kepentingan dari setiap kriteria. Adapun bobot untuk setiap kriteria diperoleh dengan data sebagai berikut :

$$
\mathrm{W}=[\mathrm{W} 1, \mathrm{~W} 2, \ldots . ., \mathrm{Wn}] \rightarrow\left[\begin{array}{lll}
50 & 30 & 20
\end{array}\right]
$$

6. Melakukan normalisasi matrix keputusan (X) ke suatu skala yang dapat diperbandingkan dengan semua rating alternatif yang ada. Dalam menormalisasi matrix $\mathrm{X}$ ke matrix $\mathrm{R}$, maka yang harus dilakukan adalah menentukan nilai $\mathrm{R}$ dari masing-masing kriteria. Matrix normalisasi $\mathrm{R}$ diperoleh persamaan:

$$
\mathrm{R}_{\mathrm{ij}}=\frac{\mathrm{X}_{\mathrm{ij}}}{\left(\operatorname{Max} \mathrm{X}_{\mathrm{ij}}\right) \text { jika } \mathrm{J} \text { adalah atribut keuntungan }}
$$


a. Untuk nilai IP (Index Prestasi), nilai normalisasi yang diperoleh yaitu sebagai berikut :

$$
\begin{aligned}
& \mathrm{R} 1.1=\frac{100}{\operatorname{Max}\{100,75,75\}}=100 \\
& \mathrm{R} 1.2=\frac{75}{\operatorname{Max}\{100,75,75\}}=75 \\
& \mathrm{R} 1.3=\frac{75}{\operatorname{Max}\{100,75,75\}}=75
\end{aligned}
$$

b. Untuk nilai Keaktifan Organisasi, nilai normalisasi yang diperoleh yaitu sebagai berikut:

$$
\begin{aligned}
& \mathrm{R} 2.1=\frac{25}{\operatorname{Max}\{25,25,75\}}=0,333 \\
& \mathrm{R} 2.2=\frac{25}{\operatorname{Max}\{25,25,75\}}=0,333 \\
& \mathrm{R} 2.3=\frac{75}{\operatorname{Max}\{25,25,75\}}=1
\end{aligned}
$$

Untuk nilai Kepemimpinan, nilai normalisasi yang diperoleh yaitu sebagai berikut:

$$
\begin{aligned}
\mathrm{R} 3.1 & =\frac{25}{\operatorname{Max}\{25,0,0\}}=1 \\
\mathrm{R} 3.2 & =\frac{0}{\operatorname{Max}\{25,0,0\}}=0 \\
\mathrm{R} 3.3 & =\frac{0}{\operatorname{Max}\{25,0,0\}}=0
\end{aligned}
$$

Dari formula di atas dapat diperoleh matriks ternormalisasi R sebagai berikut:

Tabel 7

Normalisasi Matriks R

Normalisasi

$=$\begin{tabular}{|c|c|c|c|}
\hline Alternatif & C1 & C2 & C3 \\
\hline A1 & 1 & 0.333 & 1 \\
\hline A2 & 0.75 & 0.333 & 0 \\
\hline A3 & 0.75 & 1 & 0 \\
\hline
\end{tabular}

7. Perangkingan dengan menjumlahkan setiap alternatif dari Matrix ternormalisasi $\mathrm{R}$ setiap baris dikalikan bobot $\mathrm{W}$.

$$
\begin{aligned}
& \mathrm{Ai}=(\operatorname{Rij} \times \mathrm{W} 1)+(\operatorname{Rij} \times \mathrm{W} 2)+(\operatorname{Rij} \times \mathrm{Wn}) \\
& \mathrm{A} 1=\{(1)(50)+(0.333)(30)+(1)(20)\}=79.99 \\
& \mathrm{~A} 2=\{(0.75)(50)+(0.333)(30)+(0)(20)\}=47.49 \\
& \mathrm{~A} 3=\{(0.75)(50)+(1) .30)+(0)(20)\}=67.5
\end{aligned}
$$

Dari hasil perhitungan nilai kriteria tersebut maka dihasilkan status kriteria dengan rangking nilai kriteria yang dapat digunakan dalam penentuan kelayakan calon ketua himpunan dapat dilihat pada Tabel berikut:

Tabel 8

Rangking Nilai Kriteria

\begin{tabular}{|c|l|c|c|}
\hline No & Nama & Nilai Ai & Hasil \\
\hline 1 & M Yusuf Jumain & 79.99 & Layak \\
\hline 2 & Ahmad & 47.49 & Tidak Layak \\
\hline 3 & Afriadin & 67.5 & Layak \\
\hline
\end{tabular}

\subsubsection{Penilaian Hasil Pengujian Menggunakan Blackbox Testing}

Penilaian keberhasilan perangkat lunak menggunakan Black Box Testing dapat dirumuskan sebagai berikut :

$$
\text { Hasil_blackboxtest }=\frac{\text { jumlah point }}{\text { jumlah uji }} \times 100 \%
$$

1. Hasil Pengujian Black Box Halaman Login

Hasil Black Box Login Admin 2/2 x 100\% =100\% 
2. Hasil Pengujian Black Box Halaman Kriteria Pada Admin Hasil Black Box Halaman Kriteria 7/7 x 100\% = 100\%

3. Hasil Pengujian Black Box Halaman Mahasiswa Pada Admin Hasil Black Box Halaman Mahasiswa 5/5 x 100\% = 100\%

4. Hasil Pengujian Black Box Halaman Set Periode Pada Admin Hasil Black Box Halaman Set Periode 3/3 x 100\% = 100\%

5. Hasil Pengujian Black Box Halaman Data Calon Pada Admin Hasil Black Box Halaman Data Calon 7/7 x 100\% $=100 \%$

6. Hasil Pengujian Black Box Halaman Hasil Seleksi Pada Admin Hasil Black Box Halaman Hasil Seleksi 3/3 x 100\% $=100 \%$

7. Hasil Pengujian Black Box Halaman Data Calon Pada Pengguna Hasil Black Box Halaman Data Calon 6/6 x 100\% = 100\%

8. Hasil Pengujian Black Box Halaman Hasil Seleksi Pada Pengguna Hasil Black Box Halaman Hasil Seleksi 3/3 x 100\% = 100\%

Adapun dasar dari penilaian Black Box Testing yang peneliti gunakan sebagai tingkat keberhasilan sistem yang diuji untuk kelayakan penggunaannya adalah sebagai berikut :

Tabel 9

Poin Penilaian Black Box Testing

\begin{tabular}{|c|c|c|}
\hline No. & Skala & Keterangan \\
\hline 1 & $90 \%$ sampai $100 \%$ & Sangat Layak \\
\hline 2 & $80 \%$ sampai $89,99 \%$ & Layak \\
\hline 3 & $70 \%$ sampai $79,99 \%$ & Cukup Layak \\
\hline 4 & $60 \%$ sampai $69,99 \%$ & Kurang Layak \\
\hline 5 & $0 \%$ sampai $59,99 \%$ & Tidak Layak \\
\hline
\end{tabular}

Dari hasil pengujian yang dilakukan berdasarkan metode uji black box. Semua komponen simpan, edit, update, hapus, dan cari dapat berfungsi sebagaimana mestinya. Berdasarkan hasil yang didapatkan pada metode ini dikatakan berhasil dengan nilai 100\% dan sistem ini dapat di kategorikan "Sangat Baik".

\section{KESIMPULAN}

Sistem informasi seleksi calon ketua himpunan dengan menggunakan metode SAW pada himpunan sistem informasi STMIK Adhi Guna yang dibuat pada hasil perhitungan memiliki kecocokan dengan perhitungan manual yang telah lakukan. Hal ini menunjukan bahwa sistem informasi tersebut dapat melakukan perhitungan yang sesuai dengan kriteria yang telah ditentukan.

Pengujian yang dilakukan dengan metode uji Black Box Testing didapatkan hasil yang sangat baik yakni Black Box Testing dengan presentasi hasil uji komponen $100 \%$ sehingga komponen sistem yang ada berjalan sesuai fungsinya dan dapat digunakan.

\section{SARAN}

Diharapkan bagi peneliti selanjutnya yang ingin mengembangkan sistem informasi sejenis dengan yang peneliti lakukan agar kiranya dapat dikembangkan dengan menambahkan beberapa fitur yang sesuai dengan keadaan ataupun kebutuhan untuk meningkatakan pelayanan. Dalam hal fitur-fitur yang telah ada lebih di tingkatkan lagi baik dalam segi performa maupun stabilitas.

\section{UCAPAN TERIMA KASIH}

Penulis mengucapkan terima kasih kepada STMIK Adhi Guna sebagai tempat bernaung penulis selama ini menjalani karir penulis. Selain itu Penulis juga mengucapkan terima kasih kepada teman, sahabat dan kerabat yang ada di sekitar penulis, tanpa mereka penulis tidak akan 
jadi seperti sekarang ini. Dan Terima kasih juga untuk pembaca artikel ini. Semoga ilmu ini dapat bermanfaat bagi kita semua

\section{DAFTAR PUSTAKA}

[1] Dewanto, J.I, dan Adhikara, A.MF., 2015, Sistem Penunjang Keputusan Investasi Saham dengan Metode SAW di Bursa Efek Jakarta, Skripsi, Teknik Informatika Universitas Esa Unggul, Jakarta.

[2] Djahir, Yulia dan Dewi Pratita. 2015. Bahan Ajar Sistem Informasi Manajemen. Yogyakarta : Deepublish.

[3] Erudeye. 2015. Mengenal Html CSS Javascript Dan PHP Untuk Web Designer-Pemula. Online. Tersedia Di http://www.erudeye.id. Diakses Tanggal 18 Maret 2019

[4] Erudeye. 2015. Mengenal HTML, PHP DAN MYSQL. Diambil kembali dari Erudeye: www.erudeye.id/blog

[5] J. Hutahaean. 2015. Konsep Sistem Informasi, Yogyakarta: Deepublish.

[6] Krismiaji, 2015, Sistem Informasi Akuntansi, Unit Penerbit, Yogyakarta.

[7] Ivanjelita, Lia Ayu. 2015. Sistem Pendukung Keputusan Seleksi Penerimaan Calon Asisten Praktikum. ISSN: 1411-3201. Yogyakarta: Dasi, Vol. 16, No. 4, Desember 2015: 37-46.

[8] Kumihi, E. 2018. Sistem Informasi Pemilihan Ketua Organisasi Ikatan Mahasiswa Halmahera Utara (IMAHU) Berbasis Web. STMIK Akakom Yogyakarta.

[9] Melisa Elistri, dkk 2014. Penerapan Metode Saw Dalam Sistem Pendukung Keputusan Pemilihan Jurusan Pada Sekolah Menengah Atas Negeri 8 Seluma, Universitas Dehasen Bengkulu.

[10] Meriano Setya Dwi Utomo, 2014. Penerapan Metode SAW (Simple Additive Weight) Pada Sistem Pendukung Keputusan Untuk Pemberian Beasiswa Pada Sma Negeri 1 Cepu Jawa Tengah, Universitas Dian Nuswantoro.

[11] Marlina, 2016. Sistem Penunjang Keputusan Pemilihan Ketua UKM Bodhivijja dengan Menggunakan Metode Simple Additive Weighting (SAW) (Studi Kasus : STMIK Kharisma Makasar), STMIK Kharisma Makasar.

[12] M. Dra. Hj. Yulia Djahir dan S. M. Dewi Pratita, bahan Ajar Sistem Informasi Manajemen, Yogyakarta: Deepublish, 2015.

[13] Rahayu, S. 2016. Analisa Dan Perancangan Sistem Pemilihan Ketua Himpunan Mahasiswa Studi Kasus: Program Studi Sistem Informasi Universitas Mercu Buana. Jurnal Ilmiah Fifo, 8(1), 85-96.

[14] Romney, Marshall B. dan Steinbart, (2015), "Sistem Informasi Akuntansi", Edisi 13, alihbahasa: Kikin Sakinah Nur Safira dan Novita Puspasari, Salemba Empat, Jakarta. 